\title{
Does the hospitality industry need or deserve talent?
}

\begin{abstract}
Purpose - This paper seeks to confront the most challenging issues that the hospitality industry faces. This relates to the recruitment and retention of talented future leaders. This is a long-standing issue but is one that is increasing in importance as industry changes combined with external pressures within the labour market (demographic and competitive) act to restructure the recruitment landscape in many countries.

Design/methodology/approach - This paper provides a literature-based analysis that addresses two key questions relating to the hospitality industry and talent - does the sector need talent and, controversially, does it deserve talent? The literature has been addressed on the basis of author indepth knowledge and the use of a wide range of pertinent search terms relating to the core themes of hospitality and talent management.
\end{abstract}

Findings - The paper assesses evidence with respect to both questions, framed as propositions and concludes that the current talent pipelines upon which hospitality substantially depends may not be fit for purpose and that the wider workplace culture within hospitality is not compatible with the attraction of the very best into the industry.

Research limitations/implications - The paper challenges established practice both within the hospitality industry, in terms of its workplace environment and in the way its educational partners (hospitality management schools) prepare young people for the industry. The outcomes of the analysis do not provide much by way of succour to either.

Practical implications - Implicit in this paper is a call to key stakeholders (industry, education) in the search for future leaders of the hospitality industry to address and review both the industry workplace in order to make it more attractive and rewarding for young graduates and the educational model that still dominates hospitality management programmes in preparing them for careers.

Social implications - Careers in hospitality will remain 'Cinderella' options for young graduates until action is taken by stakeholders to reposition the nature of careers on offer and the focus of programmes available in preparation for them.

Originality/value - The approach taken is the presentation of widely recognised themes in an original format.

Keywords - Hospitality; workforce; talent; hospitality management education

Paper type - Research paper 


\section{Introduction}

The topic of talent management (TM) is one addressed with increasing frequency in the general business literature but with little consensus with regard to definition (Gallardo-Gallardo and Thunnissen, 2016). TM is also a topic of significant interest within hospitality (Horner, 2017; Sheehan et al, 2018) and is an area faced with significant definitional challenges in hospitality as it is in the wider business context (D'Annunzio-Green, 2008). The same author, reflecting on her 2008 study some ten years later, also highlights that how TM is defined and framed is contingent in a way that reflects the huge diversity that is the contemporary hospitality industry across a wide range of indicators, some of which we highlight later in this paper (D'Annunzio-Green, 2018). She also notes that this context-specific understanding of TM tends to focus on organisational needs to the neglect of the individual, talented employee. Broadly, we recognise that there is widespread academic and organisational acceptance of the sentiment that underpins the definition proposed by Collings and Mellahi (2009: 205). They see TM as "activities and processes that involve the systematic identification of key positions which differentially contribute to the organizations's sustainable competitive advantage, the development of a talent pool of high potential and high performing incumbents to fill these roles, and the development of a differentiated human resource (HR) architecture to facilitate filling these positions with competent incumbents and to ensure their continued commitment to the organization". However, we also recognise the problems associated with some applications of TM that arise through this definition that, among other concerns, raise issues of elitism (Nilsson and Ellström, (2012) which are implicit in much TM analysis. Indeed, Swailes, Downs and Orr's (2014) call for a more inclusive framing for TM is, perhaps, more in tune with the hospitality industry context of this paper and reinforces similar, sector-based arguments put forward by Baum (2008).

In discussing TM in the context of hospitality, we adopt a framing that focuses primarily (but not exclusively) on the bespoke TM pipeline that has emerged over the past 125 years and is dedicated to meeting the managerial skills needs of the hospitality sector. Hospitality is unusual among business sectors in supporting and being supported by a wide range of specialist departments in universities and single purpose colleges monotechnic 'universities' ('hotel schools') (Wood, 2015), dedicated faculties within universities or colleges and, finally, provision of specialist qualifications, undergraduate or postgraduate degrees in hospitality management or similar. Wood (2015:331) notes that "this isolationism has preserved the influence of the hospitality industry on the curriculum, ensuring continuation of an operational bias" and leading to what Airey and Tribe (2000:282), quoted approvingly by Lashley (2015:367), describe as a focus on a "tyranny of relevance" in the framing of the curricula of hospitality management degrees. Historically, such 
programmes have included a strong practical and vocational 'core', frequently located around a training restaurant which contributed to the unique culture of hospitality management education (Alexander et al, 2009). However, in the universities of many developed countries, such facilities have been phased out or scaled down (Coleman et al., 2002). Such change has occurred alongside calls for a stronger social science and humanities underpinning within the education of future hospitality managers. Lashley (2015) argues this case and sees such disciplines featuring at the expense of a predominantly operational and business focus. This approach suggests a more traditionally academic profile for entrants to programmes and this raises the question as to whether potential students with abilities (talent?) in these areas can be attracted to bespoke hospitality management programmes.

There are few or any other professional fields that are supported by such an extensive specialist network of talent or skills development programmes, targeted at the managerial level, as is the case with hospitality. While health sector education may appear to have similarities to hospitality, in terms of bespoke provision, the majority of such programmes focus on technical and professional competencies (in, for example, physiotherapy and radiography) rather than generic health sector management.

This specialist focus in hospitality has consequences for recruitment and careers opportunities. It results in talent conversations between established partners (education and industry) which are both convenient in that the respective parties know where to go to promote and find talent and, arguably, lazy in that other alternative sources of talent are less likely to be tapped, for example, graduates of general business or social science degrees. As a consequence, hospitality employers are frequently not competing for talent in a wholly open graduate marketplace against businesses across the economy but confine their sourcing to a narrow range of bespoke hospitality management programmes. It is also questionable whether this single industry focus of such provision has resulted in curriculum and academic standards compromises that are not generally applied within mainstream business education (Baum, 2011). For example, hospitality management programmes frequently include modules that are tailored to sector needs in areas such as marketing and accounting and may not demand the same rigour as their generic business education counterparts.

At the same time, the hospitality industry is a sector that has seen significant growth worldwide over the past 25 years (Johanson et al, 2011) and parallel increases in educational 
provision, pointing to a 'buy-in' by all stakeholders (students, the hospitality industry, educational providers, funders in the form of government) to this bespoke pipeline. However, in a developed country context, Edelheim (2014:39) talks about the "lessening of the value given to TH\&E (Tourism, Hospitality and Events) studies in society, and through that amongst potential students. TH\&E continues to be a marginal field without an overtly intrinsic value for the nation. ...... TH\&E is valued for providing employment opportunities, but is criticized for being full of lowly paid jobs." Edelheim builds on what is a substantively damning assessment in placing such studies in the decline phase of a product lifecycle model in many countries, especially his own context, Finland.

Rather than to focus on a broad-based consideration of what talent and its management mean in the context of hospitality, it is the purpose of this paper to engage in a discourse that addresses two propositions relating to separate but linked considerations of talent. These propositions recognise that hospitality industry characteristics (for example, small businesses, weak labour markets, seasonality, precarious working opportunities) are such that the sector finds it particularly challenging to compete for what might be styled 'high level' talent in the open labour market (Baum, 2008), for example through graduate recruitment fairs (cf. Pittaway and Thedham, 2005 for their discussion of the challenges facing and ambivalence of SMEs in hospitality and tourism in relation to the graduate recruitment marketplace). Baum (2008:727), in tune with Swailes, argues that the hospitality industry needs to "interpret talent in inclusive terms, ensuring that they view the total workforce in terms of their potential to take on additional responsibility and be promoted within their department and the wider organisation". Given that, as Lewis and Heckman (2006) claim, the epithet 'talent' can apply to anyone who contributes to organisational performance, it is arguable that the scale and nature of most hospitality operations is such that this can be taken to relate to all workers. De Boeck, Meyers and Dries' (2018) depiction of a traditional and artificial distinction between those designated as 'talented' and those who are not, based on attitudinal, cognitive and behavioural criteria is problematic in this context. The structure of most hospitality businesses means that this separation is unrealistic except for business where a small corporate elite can be identified. Thus, the traditional route into hospitality management prevails which is through operational assignments where such distinction cannot be discerned. As a consequence, Baum (2008:720) argues that "talent, in the context of hospitality and tourism, however, does not necessarily mean the same thing as it might in other sectors of the economy".

The propositions here must also be seen in the context of the constantly shifting sands that constitutes the hospitality industry, notably the influence of emergent technologies and evolving 
consumer expectations that have changed the nature of hospitality delivery and the role of employees in many operations (Sheehan et al, 2018). It is also important to recognise that in relation to both the hospitality industry and its wider labour market context, interpretations of talent are place contingent. Much of the debate is framed in a developed country context although application of the key principles across cultural and economic borders to the less developed world is not necessarily valid (cf. Mahachi et al's 2015 discussion of student perceptions of management competencies in Botswana). Similarly, it is important to note the consequences of the rise of the gig economy and the impact that this has on the balance between formal and informal sectors in hospitality (Williams and Horodnic, 2017). These influences have sculpted new interpretations of hospitality roles and responsibilities within gig businesses but also within the conventional 'mainstream' as it responds to new competitive pressures. Such changes undoubtedly require a further redefinition of what constitutes talent in both technical and more generic socio-cultural and managerial terms.

Our propositions, therefore, reflect more on the here and now in international hospitality rather than on where the sector might be at some point in the future when current and potentially turbulent rebalancing of the hospitality industry between the established formal and emergent informal 'gig' sectors embedded in constant technological change has evolved further. They relate, on the one hand, to practical considerations of the roles and responsibilities that hospitality can offer to 'talented' entrants and existing employees. Complementary to this, on the other hand, our second proposition addresses ethical considerations that challenge the precariousness, quality and remuneration of work that is on offer in hospitality.

The propositions that form the backbone to this paper are:

\section{Proposition 1 (P1)}

That the contemporary hospitality industry both needs and has a meaningful role for talented recruits

\section{Proposition 2 (P2)}

That the contemporary hospitality industry deserves talented recruits and can offer talent opportunities that compete with other sectors of the economy

We will now address each in turn. 


\section{P1: That the contemporary hospitality industry both needs and has a meaningful role for talented recruits}

This proposition implies that, notwithstanding changes to the nature of work at all levels in hospitality and how companies choose to organise the delivery of hospitality products and services to their customers, there remains a need for such businesses to compete for talent in the labour market, both in terms of their recruitment and their subsequent development within the workplace. Such work changes are born of a combination of a number of drivers, notably enabling technology, increasing product and service standardisation and structural changes within hospitality that reflect new forms of relationship between consumers and service providers through gig operators such as Airbnb that have redefined the balance in the hospitality industry between formal and informal economies.

Technological impacts on industry are not new phenomena and, indeed, various forms of automation have featured as the key drivers of workplace change throughout the four industrial revolutions of the modern era. Hospitality is no exception in this regard although earlier predictions of the demise of labour intensive work in frontline and kitchen work (for example, Johnston, 1972; Levitan and Johnson, 1982) have perhaps not been wholly fulfilled even though they, in part, predate the impacts of globalisation, mass population mobility, the growth in services and rising consumerism. That said, the numbers employed in many areas of hospitality continue to decline as labour costs increase, productivity is driven up, costs are driven down especially as budget models emerge and consumer demand for lower prices exerts further pressure on hospitality service providers (Baum, 2019). As a consequence of the rise of internet-intermediated service delivery, in relative terms, work opportunities in some area have seen relative decline in both developed and less developed economies while expanding in absolute terms due to sector growth. Exploring the full extent of technological impact in this regard and its impact on hospitality demands a separate paper in its own right and is beyond the scope of this discussion (see Willcocks and Lacity, 2016 as one elaboration on this theme). Suffice to say that labour efficiencies have increased, numerically, in many developed countries, less so where labour costs and access to technology both remain low but that change varies greatly across sectors and contexts. There is a growing interest in the application of robotics to hospitality and wider frontline service work (Murphy et al, 2017; Kuo et al, 207; Ivanov and Webster, 2017; Tung and Au, 2018). For example, Qureshi and Syed (2014) investigate the prospects for robotics in the care sector, a close parallel to hospitality, and conclude that the most likely use is not so much in terms of substitution but as an aid to reducing some of the most challenging and unpleasant aspects of the work. In other contexts, the extent to which automation has and will continue to replace frontline workers in hospitality is directly contingent on the cost 
associated with the service and customer expectations that are associated with such costs. Therefore, automated check-in services in hotels are much more prevalent in budget as opposed to $5^{*}$ hotels where the customer may perceive personal 'human' service as part of the experience for which they are paying. Of course, the impact of technology is not wholly negative on the experiences of both workers and customers. Giebelhausen et al. (2014) argue that technology can be beneficial in enhancing personal connections between customers and employees in some service settings.

Globalisation of services lies at the heart of standardisation across hospitality service providers (Roberts, 2015) and has direct implications for the role of skills within the sector and the nature and scale of talent that is required. While the standardisation of products and services in itself does not require global access or delivery - as witnessed through the emergence of standardised brands such as Holiday Inn, Hilton and McDonalds in the US - the growth of standardised service delivery is closely linked to the increasing capability of enabling technology to support product and service systems, including substituting for or part delivery of elements of human interaction (as in call centres or automated check-in, as examples) (Hunt and Ivergard, 2014). Standardised service delivery in hospitality, which is one direct outcome of globalised services, demands standardised behaviour for those elements of the delivery that is not automated or robotised. This imposition of standardised service scripting, in turn, can cause detrimental outcomes in terms of customer service quality and customer citizenship behaviour (Nguyen et al, 2014). Service scripts are a frequent dimension of standardisation in hospitality and may exclude employee input (Victorino et al, 2012).

Standarisation is not exclusively about processes and procedures at the fronline in hospitality but has also impacted on the quality and demands of work across creative and managerial work (Leslie and Rantisi, 2017) and has resulted in significant managerial delayering in all sectors (Littler and Innes, 2004) including hospitality (Solnet et al, 2015; Francis and Baum, 2018) with the consequent loss of opportunity for those aspiring to entry-level management posts in the sector and, as we have already noted by reference to Edelheim (2014), evidence in a decline in demand for bespoke education in this field.

Gould (2010), in his study of fast-food 'McJobs', found that employees view their jobs as consisting of repeatedly doing a limited range of non-complex tasks (arguably an inevitable consequence of the standardisation of such work) whereas managers see the job more positively. 'McJobs', of course, is a term coined after the contribution of Ritzer (1993) and represented pejoratively by, among others, Leidner (1999:92) in arguing that “McDonald's routines were not designed to give workers power over customers. By their very nature, McJobs do not require talent for their delivery. The workers had to focus more on controlling themselves than on controlling 
others" and Knox (2016:370) who notes that "typically, McJobs are characterised by routinisation, low skills, low wages and poor career prospects". Ritzer's original thesis extends McDonalization beyond the frontline in arguing that similar principles of standardisation and specialisation apply across the services sector to include professional areas such as medicine and financial services, facilitating an overall dilution of the skills and knowledge required. This, in turn, points to the McDonaldization of junior and middle management roles in professional areas of work (Dustin, 2007) as well as sectors such as hospitality and, consequently, fewer openings for managerial talent and, of those that do remain, jobs that are less rewarding for and challenging to new graduate entrants (Hassard and Morris, 2017).

The hospitality industry, worldwide, has a long-established practice of recruiting bespoke hospitality management graduates into frontline, operational supervisory and management positions rather than into positions of general managerial responsibility, partly guided by an argument within which the central tenet is that operational exposure is a core requirement prior to future leadership responsibility. This has always been a contentious argument (Raybould and Wilkins, 2005; Harkison et al, 2011). Suh, West and Shin's (2012) study of competencies for hotel managers identifies demand for a mix of operational and inter-personal skills. The key outcome of their study is that their findings substantially confirm a large number of previous studies of competencies dating back to the 1980s. This suggests that there is no evidence of a shift to a new understanding of talent in the skills that businesses are seeking. Linked to this, Jiang and Alexakis' (2015) empirical study clearly demonstrates the differing perceptions held by hospitality managers and graduates of the skills requirements of new entrants to the industry. This includes a marked difference in the prioritisation given to organisational/ managerial skills (students) and customer service skills (employers). A consequence of these divergent interpretations of what a hospitality management graduate is and can be expected to do when they first enter the industry is that there may be a tendency for employers to discount the conventional talent indicator of formal qualifications in favour of technical skills and experience (Raybould and Wilkins, 2005). At the same time, there is also growing recognition of the impact of the changing industry environment relating to the themes addressed above on the role that hospitality management education needs to play (Lugosi and Jameson, 2017). Given these environmental changes, it is arguable that the traditional talent pipelines to entry into the hospitality industry have limited currency and applicability to the specific contemporary talent requirements of the industry. The hospitality industry in developed economies does not require operational talent in the sense and scale that might previously have been the case and what skills are required certainly do not equate to general business interpretations of what talent means. Hospitality certainly demands talent skills sets in creative 
areas such as technology innovation and applications, e-marketing, financial and revenue management and planning but these are largely common with other sectors and not specific to the industry.

Therefore, we would contend that P1 is not upheld. There is limited and declining requirement for high-end talent to meet some management functions in hospitality although specialist talent roles, some of them new and emergent, can be identified. Most educational programmes for the hospitality sector ill-prepare graduates for these roles, still emphasising an underpinning of role preparation through managerial training rather than the broad-based social science education advocated by Lashley (2015).

\section{P2: That the contemporary hospitality industry deserves talented recruits and can offer talent} opportunities that compete with other sectors of the economy

This proposition is, perhaps, rather more challenging to interrogate than P1 because it is underpinned by a clear ethical (and, arguably, subjective) dimension. The debate here centres on an assessment of the overall employment environment within the hospitality industry and whether the sector's undoubtedly challenging work environment should be a place where talented graduates and others seek to meet their career aspirations. This raises questions as to whether hospitality employment meets the test for the ILO's notion of decent work, described as existing under "conditions of freedom, equity, security and dignity, in which rights are protected and adequate remuneration and social coverage are provided" (ILO, 1999: 15) and the aspirations behind Article 8 of the UN's 2030 Agenda for Sustainable Development which advocates "full and productive employment and decent work for all" (United Nations 2015).

From a holistic, global perspective, it is difficult to dispute that the hospitality industry is associated with highly challenging employment issues. Core to these issues is the precarious nature of work in the industry (Alberti, 2016; Lee et al, 2015; Brickner and Dalton, 2017) which, Robinson et al (2019) argue, undermines claims for social sustainability within the hospitality workplace. Precariousness is evidenced against indicators that range across job security, access to income to sustain a quality of life for the employee and her/ his dependents, the ability to provide care and opportunity to all family members and the capacity to participate fully in community life (Gill and Pratt, 2008; Anderson, 2010; Arnold and Bongiovi, 2013; Quan, 2017). Precariousness can also be seen in the intersection of gender, ethnicity, disability and age in the labour market, particularly in hospitality (Alberti, 2016; Lewis et al, 2015; McDowell, 2018) where women, minorities, those with disability and young people are disproportionately likely to be employed in short-term, insecure positions than other workers, primarily men. Specifically, hospitality can be exploitative of its 
frontline employees (McDowell et al, 2009; Berg and Farbenblum, 2017); poorly paid and lacking in social respect and value (De Beer et al, 2014; Drier et al, 2018); hostile to workplace organisation (Bergene et al, 2015); exploitative of youth (Dagsland et al, 2015; Mooney, 2016); frequently condoning of employer practice that represents questionable legal and ethical standards and expectations (Poulston, 2008): and tolerating of unacceptable customer behaviour that undermines self-worth and self-respect among employees (Gaucher and Chebat, 2019). Recently, Winchenbach, Hanna and Miller (2019) haver added issues of dignity with respect to employment in this sector to the discussion, linking dignity to ILO and UN sustainability indicators. They conclude that the industry broadly fails tests of human dignity in this regard. Taken together, these indicators present a damning picture of hospitality work, around which there is little wriggle room for explanation or excuse.

Partly as a consequence, negative employee behaviours, such as cynicism and burnout, are evidenced at nearly twice the average rate in hospitality than across other sectors (Abubaker et al. 2017). Deery and Jago (2015:455) recognise these issues in terms of the talent debate when they argue that "research into the area of "talent management" in the hospitality industry, therefore, also needs to examine issues such as stress, emotional exhaustion and other personal employee dimensions".

Of course, broad generalisations about the hospitality workplace do not fairly reflect all hospitality operations across multiple contexts but, given the diversity of employment that falls under the umbrella of the sector, they can be evidenced in the context of most countries and business formats.

In a paper where the focus is on talent in the hospitality industry, it might be questioned whether the workplace issues discussed above, substantially relating to frontline and nonmanagerial staff, have any relevance. After all, talent, in most contextual uses, refers to those occupying or aspiring to occupy positions of senior responsibility, probably at corporate level, within the industry. However, even at managerial level, remuneration levels are frequently uncompetitive relative to other sectors - for example, in the UK, average pay for hospitality graduates on entry is reported to be $£ 17,000$ which is significantly lower than equivalents in most other sectors and considerably less than the average graduate entry point of $£ 29,000$ across all sectors (Allaboutcareers, 2019). Also, at the heart of these indicative challenges to decent work in hospitality is, arguably, the absence of sustainable HRM practices in many hospitality businesses which must act as a barrier to talent attraction and retention (Baum et al, 2016; Baum, 2018a). It is worthwhile examining what sustainable HRM actually means in this context. Ehnert et al $(2016,90)$ 
define it as " the adoption of HRM strategies and practices that enable the achievement of financial, social and ecological goals, with an impact inside and outside of the organisation and over a longterm time horizon while controlling for unintended side effects and negative feedback". Earlier, the same author (2009) had identified the key components of sustainable HRM practice as

- attracting and retaining talent (author italics) and being recognised as an 'employer of choice';

- maintaining employee health and safety;

- investing into the skills of the workforce on a long-term basis by developing critical competencies and lifelong learning;

- supporting employees' work-life balance and work-family balance;

- managing aging workforces; creating employee trust, employee trustworthiness and sustained employment relationships; exhibiting and fostering (corporate) social responsibility towards employees and their communities ; and

- maintaining a high quality of life for employees and communities.

It is arguable that many of these conditions are not consistently present in the hospitality industry and, indeed, are notable for their absence in many businesses. It can also be contended that challenging conditions and issues in hospitality employment persist and prevail despite widespread exposure in the academic, policy and popular media space (see, as a sample among many, the initiative reported by Walker, 2019). This may well be because of the industry's failure to attract talented recruits with the vision and understanding to recognise that such practices are not sustainable and are not compatible with positive business outcomes.

Moreover, the reality of the hospitality industry's failure to offer sustainable employment opportunities to workers at all levels inflicts major reputational damage on the sector which, in turn, has an influence on the choices made by those entering both education after high school and seeing employment upon graduation. In countries such as the UK, entry grades to most hospitality management programmes are significantly lower than is the case with general business degrees and hospitality management programmes are generally offered by lower ranked institutions. As we have noted, on graduation, salaries offered in the hospitality sector vary greatly but, overall, are significantly below the national average in the UK (The Complete Universities Guide, 2018) and are on par with para-medical and creative industry opportunities at the bottom of the scale. Similarly, hospitality features strongly among those areas of work where graduate underemployment is widespread (Abel and Deitz, 2016; Acosta-Ballesteros et al, 2018), suggesting that the industry's propensity to place graduates in frontline positions at commencement remains a real issue. This is also an issue of gender in that women are disproportionately represented in recruitment to 
hospitality management programmes (Santero-Sanchez et al, 2015) and, on graduation, are also over-represented among those underemployed in the workforce (Kamerāde and Richardson, 2018).

Returning to P2, therefore, it can be concluded that many employers in the hospitality industry do not provide an environment that seeks to support and nurture talent. The underlying employment issues that characterise the sector are such that the industry does not meet reasonable criteria for the spirit or intent of the notion of decent work and, likewise, falls some way short of delivering on the objectives of the UN's Sustainable Development Goals. With this indictment, it is difficult to conclude other than that the industry does not deserve talent, however broad a definition is employed to define such talent attributes (Baum, 2008).

\section{Conclusions}

This paper is critical in its assessment of the changing hospitality industry context and its requirements for and capacity to make use of talent on a significant scale. That there is limited use for talent in specialist areas and within a narrow segment of the upscale market is conceded but there is by no means an industry-wide demand for the attributes generally associated with talent. There is also little evidence, going forward, that this will change in the foreseeable future. This paper also questions whether the on-going and challenging employment culture of the industry is such that it is actually deserving of such talent and the investment that exceptional young people may place in their careers. While it is recognised that many talented young people do join the industry and some make rewarding careers in hospitality, others leave within a relatively shortperiod of time, pointing to serious graduate retention issues within the sector (Zainal et al, 2012; Brown et al, 2014; Nachmias and Walmsley, 2015). While the hospitality industry has it within its power to affect change with regard to P2 as delineated in this paper (Baum, 2019), whether there is the leadership or will do so in hospitality is altogether another question. The limited progress we have seen over the past 80 years suggests not.

It is also recognised that the hospitality industry is hugely diverse and that generalisations about the sector in terms of its workplace environment and growth opportunities are difficult to make. That said, the conclusions reached here are that the existing talent pipelines upon which the hospitality industry substantially depends are not wholly fit for purpose in that they prepare graduates for an industry world that is fast shrinking and fast changing. As a result, there is an urgent need to rethink the routes available to graduates entering the hospitality sector, including questioning the place of bespoke (and, frequently, second-class) management degrees. It is also the case that, if the hospitality industry does indeed wish to recruit from the most talented pool in the graduate labour market, there is a real need for cultural and organisational change within both large 
and small organisations. In this, we wholly endorse Baum's (2019:49) aspirational siren call for change to an industry culture where

Hospitality and its value chains meet the highest ethical standards with respect to work and employment in all sectors and levels within the industry, respecting the rights and dignity of each individual worker and offering them opportunity to gain just reward for their efforts, and to grow and progress, irrespective of gender, ethnicity, sexual orientation, age or disability.

In this paper, we have challenged established practice both within the hospitality industry, in terms of its workplace environment and the opportunities it provides for young graduates and in the way that its educational partners (hospitality management schools) prepare young people for the industry. The outcomes of the analysis do not provide much by way of succour to either. Implicit in this paper is a call to key stakeholders (industry, education), in their search for future leaders of the hospitality industry to critically address and review both the industry workplace in order to make it more attractive and rewarding for young graduates and the educational model that still dominates the hospitality management programmes that are designed to prepare them for such work. Such change cannot be easily enacted in an industry environment of increasing competition and a labour market where real ability is greatly valued and rewarded at levels that appear to be out of the reach of the hospitality industry as it is currently configured. It may well be that real change will only take place with the revival of high quality vocational and professional educational programmes designed to prepare graduates for the leadership in technical domains of hospitality while business leadership is acquired through non-specialist routes where direct competition with other business sectors for talent will occur.

Without such ground-changing change, it is unlikely that the hospitality industry will be able to compete effectively for the talented youth of tomorrow in the employment marketplace. 


\section{References}

Abel, J. and Deitz, R. (2016) Underemployment in the esrly careers of college graduates following the great recession, Working Paper 22654, Cambridge, Mass.: National Bureau of Economic Research, http://www.nber.org/papers/w22654

Abubakar, A. M., Namin, B. H., Harazneh, I., Arasli, H., and Tunç, T. (2017). Does gender moderates the relationship between favoritism/nepotism, supervisor incivility, cynicism and workplace withdrawal?: A neural network and SEM approach, Tourism Management Perspectives, 23: 129-139

Acosta-Ballesteros, J., Osorno-del Rosal, M. and Rodríguez-Rodríguez, O.M. (2018)

Underemployment and employment among young workers and the business cycle in Spain: the importance of education level and specialisation, Journal of Education and Work, 31(1): 28-46

Airey, D. and Tribe, J. (2000), "Education for hospitality", in Lashley, C. and Morrison, A. (Eds), In Search of Hospitality: Theoretical Perspectives and Debates, Butterworth-Heinemann, Oxford, 276-291.

Alberti, G. (2016) Mobility strategies, 'mobility differentials' and 'transnational exit': the experiences of precarious migrants in London's hospitality jobs, Work, Employment and Society, 28(6): 865-881

Alexander, M., Lynch, P.A. and Murray, R. (2009) Reassessing the core of hospitality management education: the continuing importance of training restaurants, Journal of Hospitality, Leisure, Sport and Tourism Education, 8 (1): 55-69

Allaboutcareers (2019) How much should a graduate earn?, accessed at https://www.allaboutcareers.com/careers-advice/looking-for-a-job/how-much-should-a-graduateearn on 10th February 2019

Anderson, B. (2010) Migration, immigration controls and the fashioning of precarious workers, Work, Employment and Society, 24(2), 300-317

Arnold, D. and Bongiovi, J. (2013). Precarious, informalizing, and flexible work. transforming concepts and understandings, American Behavioral Scientist, 57(3), 289-308

Baum, T. (2008) Implications of hospitality and tourism labour markets for TM strategies, International Journal of Contemporary Hospitality Management, 20(7): 720-729

Baum, T. (2011) A complacent mediocrity. Has the tourism industry let higher education off the hook?, Keynote presentation to the Tourism Education Futures Initiative (TEFI) Conference, Activating Change in Tourism Education, Temple University, Philadelphia, May

Baum, T. (2018a). Sustainable human resource management as a driver in tourism policy and planning: a serious sin of omission? Journal of Sustainable Tourism. 26(6): 1-38

Baum, T. (2018b) Changing employment dynamics within the creative city: exploring the role of 'ordinary people' within the changing city landscape, Economic and Industrial Democracy, DOI: $10.1177 / 0143831 \times 17748371$

Baum, T. (2019) Hospitality employment 2033: A backcasting perspective (invited paper for 'luminaries' special issue of International Journal of Hospitality Management), International Journal of Hospitality Management, 76(B): 45-52 
Baum, T., Cheung, C., Kong, H., Kralj, A., Mooney, S., Nguyen Thi Thanh, H., Ramachandran, S., Dropulic Ruzic, M. and Siow, M.L. (2016) Sustainability and the Tourism and Hospitality Workforce: A Thematic Analysis, Sustainability, 8(8): 809-830

Berg, L., and Farbenblum, B. (2017). Wage-theft in Australia: Findings of the National Temporary Migrant Work Survey. Sydney, Australia: Migrant Worker Justice Initiative

Bergene, A. C., Boluk, K., and Buckley, E. (2015). Examining the opportunities and challenges of union organisation within the hospitality industry, in (Eds) Jordhus-Lier, D. and Underthun, A. A hospitable world? Organising work and workers in hotels and tourist resorts, London: Routledge, 195-212

Brickner, R. and Dalton, M. (2017) Organizing Baristas in Halifax Cafes: Precarious Work and Gender and Class Identities in the Millennial Generation, Critical Sociology, DOI:

10.1177/0896920517730671

Brown, E., Arendt, S. and Bosselman, R. (2014) Hospitality management graduates' perceptions of career factor importance and career factor experience, International Journal of Hospitality Management, 37: 58-67

Burgen, C. (2018) Chambermaids' revolt aims to shame Spain's rogue employers, The Guardian, $15^{\text {th }}$ July, accessed at https://www.theguardian.com/travel/2017/jul/15/spanish-hotel-cleanersfightback-exploitation on 18th August 2018

Coleman, P., Jackson, R., Ritchie, C., Roberts, A. and Snelgrove, M. (2002). An Evaluation of the Content, Appropriateness and Academic Rigour of Food and Beverage Modules within Undergraduate Hospitality Management Programmes. The Welsh School of Hospitality, Tourism and Leisure Management, LTSN, 22

Dagsland, A.H., Mykletun, R. and Einarsen, S. (2015) "We're not slaves - we are actually the future!" A follow-up study of apprentices' experiences in the Norwegian hospitality industry, Journal of Vocational Education and Training, 67(4): 460-481

D'Annunzio-Green, N. (2008), Managing the talent pipeline: towards a greater understanding of senior managers' perspectives in the hospitality and tourism sector, International Journal of Contemporary Hospitality Management, 20(7): 807-819

D'Annunzio-Green, N. (2018) Cornerstones of TM as a strategic priority in the hospitality, Worldwide Hospitality and Tourism Themes, 10(1): 5-13

De Beer, A., Rogerson, C., and Rogerson, J. (2014). Decent work in the South African tourism industry: Evidence from tourist guides. Urban Forum, 25(1), 89-103

De Boeck, G., Meyers, M.C. and Dries, N. (2018) Employee reactions to TM: Assumptions versus evidence. Journal of Organizational Behavior, 39: 199-213

Deery, M. and Jago, L. (2015) Revisiting TM, work-life balance and retention strategies, International Journal of Contemporary Hospitality Management, 27(3), pp.453-472

Dreier, P. and Fleming, D. (2018) Working for the Mouse. A Survey of Disneyland Resort Employees, Occidental College, accessed at https://www.oxy.edu/sites/default/files/assets/UEPI/ERt\%20Disneyland\%20final\%202-202018\%20\%281\%29.pdf on $1^{\text {st }}$ April 2018 
Dustin, D. (2007) The McDonaldization of Care Work, London: Routledge

Edelheim, J. (2014) Ontological, epistemological and axiological issues, In (eds) Dredge, D., Airey, D. and Gross, M. The Routledge Handbook of Tourism and Hospitality Education, London: Routledge, $30-42$

Francis, H. and Baum, T. (2018) HR transformation within the hotel industry: building capacity for change, Worldwide Hospitality and Tourism Themes, 10(1): 86-100

Gallardo-Gallardo, E, and Thunnissen, M. (2016) Standing on the shoulders of giants? A critical review of empirical TM research, Employee Relations, 38(1): 31-56

Gaucher, B. and Chebat, J-C. (2019) How uncivil customers corrode the relationship between frontline employees and retailers, Journal of Retailing and Consumer Services,

https://doi.org/10.1016/j.jretconser.2018.09.012

Giebelhausen, M., Robinson, S., Sirianni, N. and Brady, M. (2014), 'Touch versus Tech: When Technology Functions as a Barrier or a Benefit to Service Encounters, Journal of Marketing, 78(4): 113-124

Gill, R. and Pratt, A. (2008). In the social factory? Immaterial labour, precariousness and cultural work. Theory, Culture and Society, 25(7-8), 1-30

Harkison, T., Poulston, J. and Kim, J-H. G. (2011) Hospitality graduates and managers: the big divide, International Journal of Contemporary Hospitality Management, 23(3): 377-392

Hassard, J. and Morris, J. (2017) Corporate restructuring, work intensification and perceptual politics: Exploring the ambiguity of managerial job insecurity, Economic and Industrial Democracy, https://doi.org/10.1177/0143831×17710733

Horner, S. (Ed.) (2017), TM in Hospitality and Tourism, Oxford: Goodfellow

Hunt, B. and Ivergard, T. (2014) Designing service excellence. People and Technology, Boca Raton, FL: CRC Press

International Labour Organization (ILO). (1999). Decent work. Report of the Director General to the 87th meeting of the international labour conference, Geneva: International Labour Office

Ivanov, S., and Webster, C. (2017). Adoption of robots, artificial intelligence and service automation by travel, tourism and hospitality companies - a cost-benefit analysis., Paper to International Scientific Conference Contemporary tourism - traditions and innovations, 19- 21 October 2017, Sofia University

Jiang, L. and Alexakis, G. (2017) Comparing students' and managers' perceptions of essential management competencies in the hospitality industry: An empirical study, Journal of Hospitality, Leisure, Sport and Tourism, 20: 32-46

Johanson, M., Ghiselli , R. Shea, L. and Roberts, C. (2011) Changing Competencies of Hospitality Leaders: A 25-Year review, Journal of Hospitality \& Tourism Education, 23(3): 43-47 
Johnston, D. (1972) The future of work: Three possible alternatives, Monthly Labor Review, 95(5): 311

Kamerāde, D. and Richardson, H. (2018) Gender segregation, underemployment and subjective wellbeing in the UK labour market, Human Relations, 71(2): 285-309

Knox, A. (2016) Coffee nation: an analysis of jobs in Australia's café industry, Asia Pacific Journal of Human Resources, 54(3): 369-387

Kuo, C-M, Chen, L-C. and Tseng, C-Y. (2017) Investigating an innovative service with hospitality robots, International Journal of Contemporary Hospitality Management, 29(5): 1305-1321

Lashley, C. (2015) Hospitality studies: escaping the tyranny?, Quality Assurance in Education, 23(4): 364-377

Lee, D., Hampton, M. and Jeyacheya, J. (2015) The political economy of precarious work in the tourism industry in small island developing states, Review of International Political Economy, 22(1): 194-223

Leidner, R. (1999) Emotional labor in service work, Annals of the American Academy of Political and Social Science 561: 81-95

Leslie, D. and Rantisi, N. (2017) Deskilling in cultural industries: Corporatization, standardization and the erosion of creativity at the Cirque du Soleil, Geoform, https://doi.org/10.1016/j.geoforum.2017.09.011

Levitan, S. and Johnson, C. (1982) The future of work: does it belong to us or to the robots?, Monthly Labor Review, 105(9): 10-14

Lewis, H., Dwyer, P., Hodkinson, S. and Waite, L. (2015) Hyper-precarious lives: Migrants, work and forced labour in the Global North, Progress in Human Geography, 39(5), 580-600

Lewis, R. and Heckman, R. (2006), TM: a critical review, Human Resource Management Review, 16(2): 139-54

Littler, C. and Innes, P. (2004) The Paradox of Managerial Downsizing, Organization Studies, 25(7),: 1159-1184

Lugosi, P. and Jameson, S. (2017) Challenges in hospitality management education: Perspectives from the United Kingdom, Journal of Hospitality and Tourism Management, 31: 163-172

McDowell, L., Batnitzky, A. and Dyer, S. (2007). Division, segmentation and interpellation: The embodied labors of migrant workers in a greater London hotel, Economic Geography, 83(1): 1-25

McDowell, L. (2018) Moving stories: precarious work and multiple migrations, Gender, Place and Culture, 25(4): 471-488

McGhee, A. (2018) The reality of cheap airfares: Jetstar under fire over foreign crews' pay and work on domestic sectors, $A B C$ News, $14^{\text {th }}$ August, accessed at http://www.abc.net.au/news/2018-0814/jetstar-under-fire-over-foreign-cabin-crews-pay-domestic-flights/10107814 on 14th August 2018 
McGreal, C. (2018) Is Bezos holding Seattle hostage? The cost of being Amazon's home, The Guardian, $4^{\text {th }}$ July 2018 accessed at https://www.theguardian.com/cities/2018/jul/04/is-bezosholding-seattle-hostage-the-cost-of-being-amazons-home?CMP=share bth link on $5^{\text {th }}$ July 2018

Makachi, D., Ndhlovu, N., Montle Siya, K., Tsheko, T., Moswete, N. and Monkgogi, L. (2015) A Comparative Study of Students' Perceptions of Managerial Competencies and their Implications on Tourism and Hospitality Education in Botswana, Botswana Journal of Business, 8(1): 98-110

Mooney, S. (2016), Wasted youth in the hospitality industry: older workers' perceptions and misperceptions about younger workers, Hospitality and Society, 6 (1), 9-30

Murphy, J., Hofacker, C. and Gretzel, U. (2017) Dawning of the age of robots in hospitality and tourism: Challenges for teaching and research, European Journal of Tourism Research, 15: 104-111

Nachmias, S. and Walmsley, A. (2015) Making career decisions in a changing graduate labour market: A Hospitality perspective, Journal of Hospitality, Leisure, Sport and Tourism Education, 17: 50-58

Nguyen, H., Groth, M., Walsh, G. and Hennig-Thurau, T. (2014) The impact of service scripts on customer citizenship behaviour and the moderating role of employee customer orientation, Psychology and Marketing, 31(12): 1096-1109

Nilsson, S. and Ellström, P-E. (2012) Employability and TM: challenges for HRD practices, European Journal of Training and Development, 36(1): 26-45

Orwell, G. (1933) Down and out in Paris and London, London: Penguin

Pittaway, L. and Thedham, J. (2005) Mind the Gap' Graduate Recruitment in Small Businesses, International Small Business Journal, 23(4): 403-426

Poulston, J. (2008). Rationales for employee theft in hospitality: Excuses, excuses. Journal of Hospitality and Tourism Management, 15, 49-58

Quan, M. (2017). Precarious Work in Europe: Assessing Cross-National Differences and Institutional Determinants of Work Precarity in 32 European Countries. Research in the Sociology of Work, 31, 273-306

Qureshi, M. and Syed, R. (2014) The Impact of Robotics on Employment and Motivation of Employees in the Service Sector, with Special Reference to Health Care, Safety and Health at Work, 5(4): 198-202

Raybould, M. and Wilkins, H. (2005) Over qualified and under experienced: Turning graduates into hospitality managers, International Journal of Contemporary Hospitality Management, 17(3): 203-216

Ritzer, G. (1993) The McDonaldization of Society, Thousand Oaks, CA: Sage

Roberts, J., (2015) Globalization of Services in (eds) Bryson, J. R. and Daniels, P. W., Handbook of Service Business: Management, Marketing, Innovation and Internationalisation, Cheltenham : Edward Elgar, 257-277

Robinson, R., Martins, A., Solnet, D. and Baum, T. (2019) Sustaining precarity: critically examining tourism and employment, Journal of Sustainable Tourism, DOI: 10.1080/09669582.2018.1538230 
Santero-Sanchez, R., Segovia-Pérez, M., Castro-Nuñez, B., Figueroa-Domecq, C. and Talón-Ballestero, P. (2015) Gender differences in the hospitality industry: A job quality index, Tourism Management, 51: $234-246$

Sheehan, M., Grant, K and Garavan, T. (2018) Strategic TM: A macro and micro analysis of current issues in hospitality and tourism, Worldwide Hospitality and Tourism Themes, 10(1): 28-41

Solnet, D., Kralj, A. and Baum, T. (2015) 360 degrees of pressure: the changing role of the HR professional in the international hospitality industry Journal of Hospitality and Tourism Research 39(2): 271-292

Spring, M. (2018) Wimbledon cleaning staff 'take food from bins due to low pay', The Guardian, 16 July, accessed at https://www.theguardian.com/sport/2018/jul/16/wimbledon-cleaning-staff-foodfrom-bins-low-pay on 13th August 2018

Suh, E., West, J. and Shin, J. (2012) Important competency requirements for managers in the hospitality industry, Journal of Hospitality, Leisure, Sport and Tourism Education, 11, 101-112

Swailes, S., Downs, Y., \& Orr, K. (2014). Conceptualising inclusive TM: Potential, possibilities and practicalities. Human Resource Development International, 17(5), 529-544

The Complete Universities Guide (2018) Average Graduate Salaries, accessed at https://www.thecompleteuniversityguide.co.uk/careers/what-do-graduates-do-andearn/\#Graduatesearn

Tung, V. W-S and Au, N. (2018) Exploring customer experiences with robotics in hospitality, International Journal of Contemporary Hospitality Management, https://doi.org/10.1108/IJCHM-06-2017-0322

United Nations 2015. "Transforming our world: the 2030 Agenda for Sustainable Development." https://sustainabledevelopment.un.org/content/documents/21252030\%20Agenda\%20for\%20Sustai nable\%20Development\%20web.pdf (accessed $7^{\text {th }}$ February 2019)

Walker, A. (2019) Hospitality abuse: new website to encourage workers to speak out, The Guardian, $31^{\text {st }}$ January, https://www.theguardian.com/business/2019/jan/31/restaurant-industry-plagued-byabuse-insiders-warn?CMP=share btn link (accessed $8^{\text {th }}$ February 2019)

Willcocks, L. and Lacity, M. (2016) Service automation robots and the future of work. Ashford: SB Publishing

Williams, C. and Horodnic, I. (2017) Regulating the sharing economy to prevent the growth of the informal sector in the hospitality industry, International Journal of Contemporary Hospitality Management, 29(9): 2261-2278

Winchenbach, A., Hanna, P. and Miller, G. (2019): Rethinking decent work: the value of dignity in tourism employment, Journal of Sustainable Tourism, DOI: 10.1080/09669582.2019.1566346

Wood, R. (1997). Working in Hotels and Catering, London: International Thomson Business Press

Wood, R. (2015) 'Folk' understandings of quality in UK higher hospitality education, Quality Assurance in Education, 23(4): 326-338 
Working Partnerships USA (2016) Tech's Invisible Workforce, accessed at http://www.siliconvalleyrising.org/files/TechsInvisibleWorkforce.pdf on 7th July 2018

Zainal, A., Radzi, S.M.,Hashim, R., Chik, C.T. and Abu, R. (2012) Current Issues in Hospitality and Tourism. Research and Innovation, London: CRC Press 